\title{
РЕКОНСТРУКЦИЯ ЗАГРЯЗНЕНИЯ ТЕРРИТОРИИ ПОЛУОСТРОВА РЫБАЧИЙ МУРМАНСКОЙ ОБЛАСТИ ТЯЖЕЛЫМИ МЕТАЛЛАМИ
}

\section{Даувальтер В.А. ${ }^{1}$, Терентьев П.М. ${ }^{1}$, Денисов Д.Б. ${ }^{1}$, У дачин В.Н. ${ }^{2}$, Филиппова К.А. ${ }^{2}$, Борисов А.П.}

${ }^{l}$ Институт проблем промышиленной экологии Севера КНЦ PAH, Anamumbl, vladimir@inep.ksc.ru

${ }^{2}$ Институт минералогии УрО РАН, Миасс

${ }^{3}$ Институт геохимии и аналитической химии им. В.И. Вернадского РАН, Москва

Как известно, водоемы служат коллекторами всех видов загрязнения. Донные отложения (ДО) водоемов накапливают «сведения» о потоках элементов в биосфере в историческом срезе [1]. Они являются важным источником информации о климатических, геохимических, экологических условиях, существовавших на водосборе и в самом водоеме, позволяют оценить современное экологическое состояние воздушной и водной сред окружающей территории. Исследование химического состава толщи ДО позволяет восстановить историю условий формирования озер, базируясь на определении фоновых значений содержания различных элементов в ДО и изменений их поступления в течение длительного периода времени. Особую научную значимость они приобретают, когда известна скорость осадконакопления, что позволяет реконструировать хронологию процессов, происходящих на водосборе и в самом озере [3, 4].

В рамках проекта «Коларктик» для изучения экологического состояния озер и изучения изменений интенсивности антропогенной нагрузки на приграничную территорию между Россией, Нор-

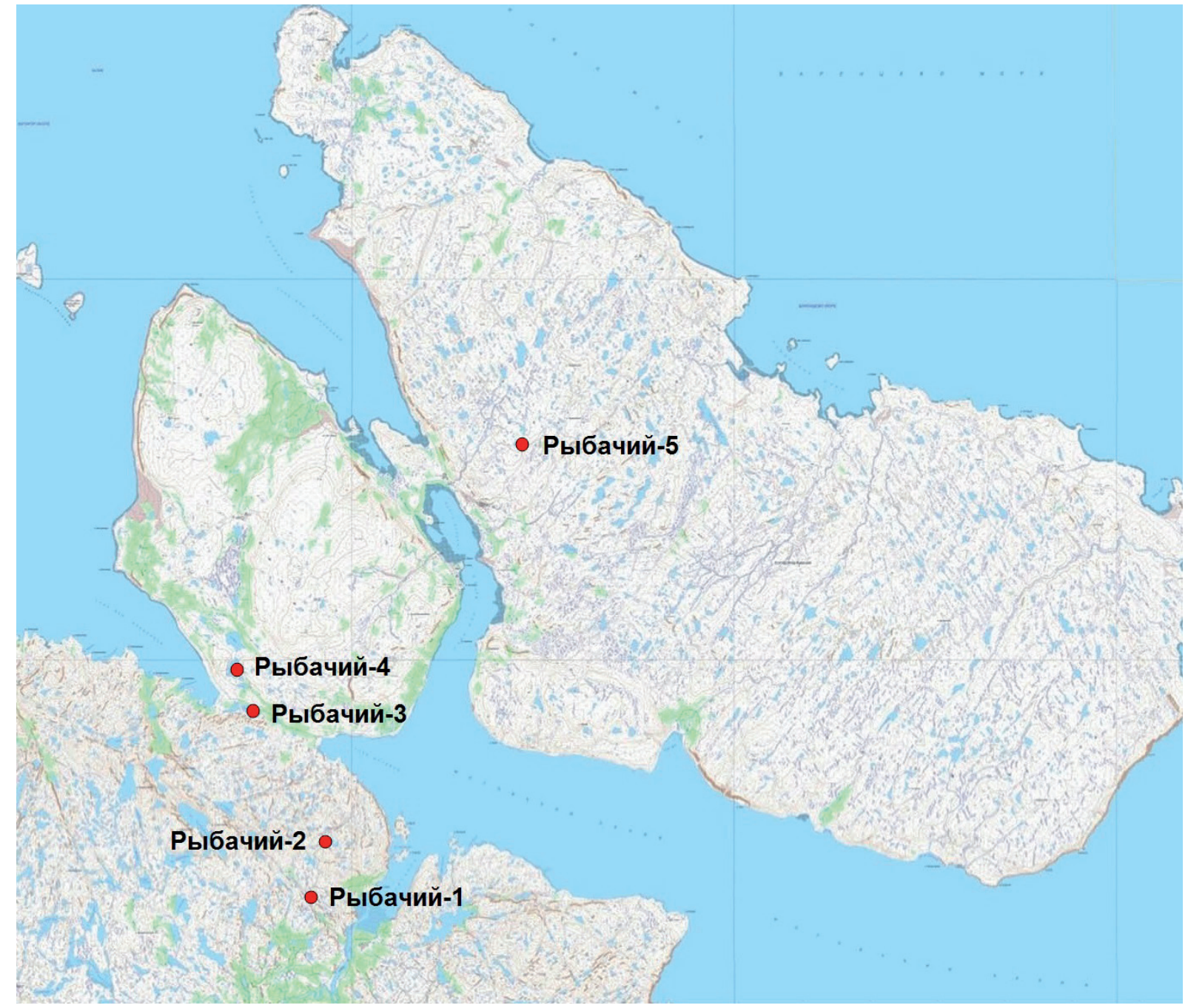

Рис. 1. Схема расположения исследуемых озер. 

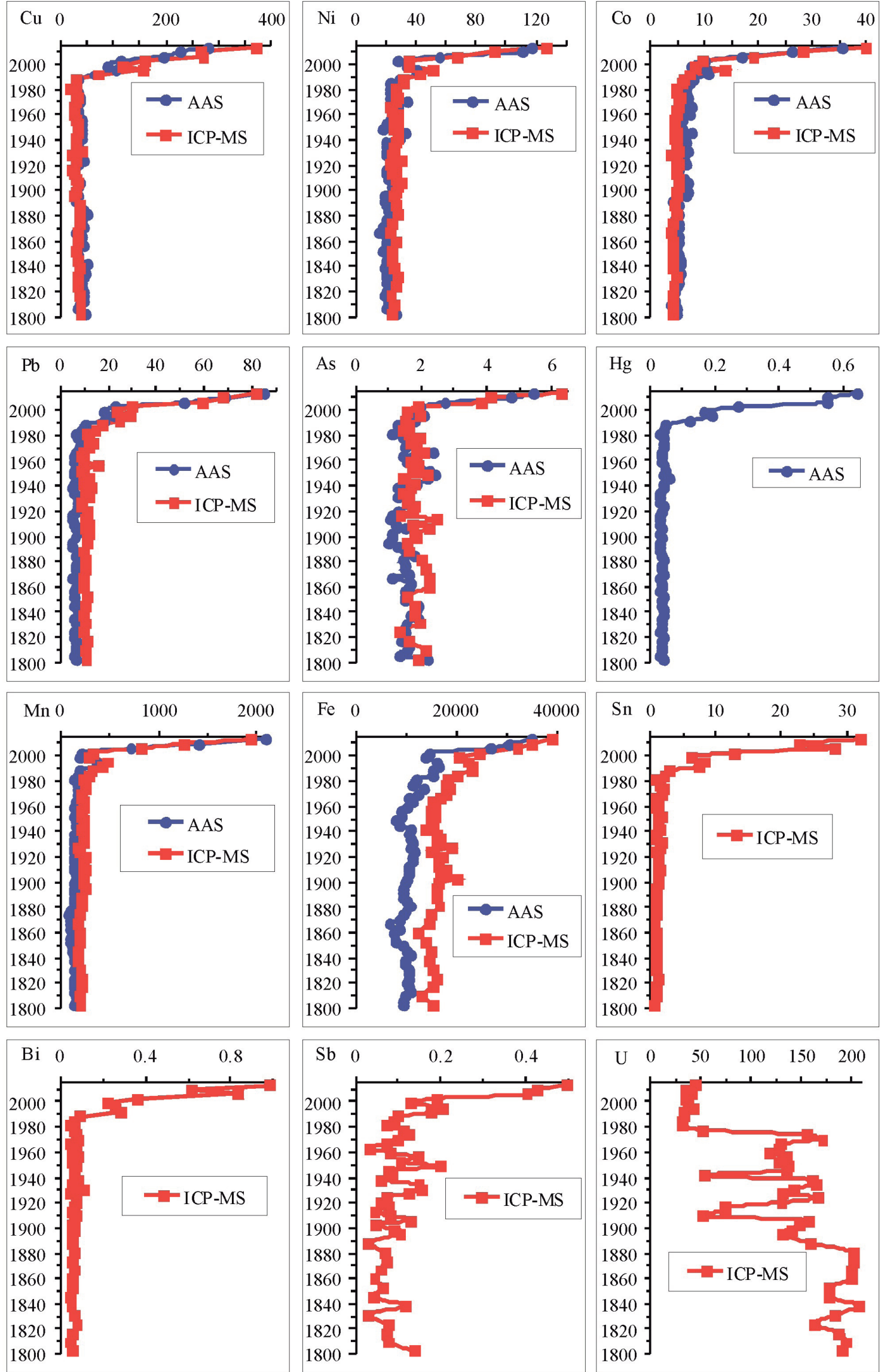

Рис. 2. Вертикальное распределение элементов в датируемых ДО оз. Рыбачий-1. 
вегией и Финляндией в ноябре 2015 г. были проведены исследования по вертикальному распределению концентраций элементов в ДО 5 озер п-ова Рыбачий (рис. 1). Комбинат «Печенганикель» является ближайшим крупным источником загрязнения и располагается от исследуемых озер на расстоянии 50-70 км, поэтому разумно ожидать увеличения содержаний тяжелых металлов (ТМ) в поверхностных слоях ДО, хотя ранее проведенными исследования было установлено, что ареал интенсивного загрязнения ограничивается радиусом 40 км вокруг комбината [1].

Колонки ДО на исследуемых водоемах взяты в наиболее глубоких местах отборником колонок ДО открытого гравитационного типа (внутренний диаметр 44 мм) с автоматически закрывающейся диафрагмой. Длина колонок ДО составляла от 10 до 38 см, в зависимости от условий их формирования и физико-химических особенностей. Колонки ДО были разделены на слои по 0.5 см, помещены в полиэтиленовые контейнеры и отправлены в лабораторию для анализа, где они хранились при температуре $4^{\circ} \mathrm{C}$ до анализа. Определение содержания элементов $(\mathrm{Ni}, \mathrm{Cu}, \mathrm{Co}, \mathrm{Zn}$, $\mathrm{Cd}, \mathrm{Pb}, \mathrm{Hg}, \mathrm{Mn}, \mathrm{Fe}, \mathrm{Ca}, \mathrm{Mg}, \mathrm{Na}, \mathrm{K}, \mathrm{Al}, \mathrm{Cr}, \mathrm{P}, \mathrm{Sr}$ п проводились в ИППЭС КНЦ РАН методом атомноабсорбционной спектрометрии (AAS) после обработки проб концентрированной $\mathrm{HNO}_{3}$ в тефлоновых бомбах при температуре $140^{\circ} \mathrm{C}$ и в ИМ УрО РАН методом масс-спектрометрии с индуктивно связанной плазмой (ICP-MS, Agilent 7700x) после обработки проб смесью $\mathrm{HF}+\mathrm{HCl}+\mathrm{HNO}_{3}$ в системе микроволновой подготовки Berghof. Подробно методика определения содержания элементов описана ранее $[1,2,5]$.

Анализ содержания радионуклидов и расчет средних скоростей осадконакопления был выполнен для оз. Рыбачий-1 в Институте геохимии и аналитической химии им. В. И. Вернадского (ГЕОХИ РАН). Определение активности радионуклидов ${ }^{137} \mathrm{Cs}$ и ${ }^{210} \mathrm{~Pb}$ в пробах ДО проводили на низкофоновом гамма-спектрометре Canberra Industries с полупроводниковым детектором на основе особо чистого германия с активным диаметром 70 мм и толщиной 25 мм. Рассчитанные величины абсолютных скоростей осадконакопления в оз. Рыбачий-1 по ${ }^{137} \mathrm{Cs}$ и ${ }^{210} \mathrm{~Pb}$ составили соответственно $0.14 \pm 0.03$ и $0.15 \pm 0.03$ см/год. Учитывая среднюю скорость осадконакопления 0.14 см/год были построены графики вертикального распределения элементов в датируемых ДО оз. Рыбачий-1 по результатам определений в ИППЭС КНЦ РАН (AAS) и в ИМ УрО РАН (ICP-MS) (рис. 2). Совпадение результатов, полученных в двух лабораториях и использующих различное аналитическое оборудование, говорит о высококачественной работе обеих лабораторий, несмотря на некоторое различие в способах пробоподготовки к анализам.

На комбинате «Печенганикель» перерабатываются медно-никелевые сульфидные руды, представленные такими минералами, как пентландит (Fe,Ni) $\mathrm{S}_{8}$, халькопирит $\mathrm{CuFeS}_{2}$, кобальтин $(\mathrm{Co}, \mathrm{Ni})$ $\mathrm{AsS}$, никелин NiAs, галенит $\mathrm{PbS}$, сфалерит $\mathrm{ZnS}$, хромит $\mathrm{FeCr}_{2} \mathrm{O}_{4}$, минералами платиновой группы (арсениды, теллуриды, селениды) и другими [6]. Поэтому в выбросах комбината, помимо соединений $\mathrm{S}, \mathrm{Ni}$ и $\mathrm{Cu}$, присутствуют и сопутствующие им $\mathrm{TM}$ и металлоид ( $\mathrm{Co}, \mathrm{Zn}, \mathrm{Pb}, \mathrm{Cr}, \mathrm{Cd}, \mathrm{Hg}, \mathrm{As}), \mathrm{Fe}$, $\mathrm{Se}, \mathrm{Te}$, а также петрогенные щелочные и щелочноземельные металлы и другие элементы в составе производственной пыли комбината. В поверхностных слоях ДО исследуемых водоемов отмечается довольно значительное увеличение концентраций $\mathrm{Cu}, \mathrm{Ni}, \mathrm{Co}, \mathrm{As}$ по направлению к поверхности ДО (рис. 2), датируемое 1980-ми годами, что, вероятно, связано с атмосферными выбросами комбината «Печенганикель». Начало загрязнения высокотоксичными халькофильными элементами $\mathrm{Pb}$ и $\mathrm{Hg}$ датируется также 80-ми годами прошлого столетия. Впервые для озер Мурманской области зафиксировано увеличение содержания $\mathrm{Sn}, \mathrm{Bi}$ и $\mathrm{Sb}$ в поверхностных слоях ДО (от 17 до 50 раз относительно фоновых содержаний), что, вероятно, связано с выбросами комбината, а также снижение содержания U начиная с 1970-х гг. более чем в 6 раз, что, можно предположить, связано с прекращением испытаний ядерного оружия на Новой Земле (рис. 2). Значительное увеличение содержания большинства ТМ в ДО исследуемых озер в 1980-е гг. связано, скорее всего, с началом переработки норильской руды и интенсивным ростом медно-никелевого производства на комбинате «Печенганикель» в 70-80-е гг. XX в. 
Таблица 1. Концентрации тяжелых металлов (результаты ИППЭС КНЦ РАН) в поверхностных (0-1 см) и фоновых слоях (вторая строка каждого озера) ДО, значения коэффициентов (Cf) и степени $(\mathrm{Cd})$ загрязнения озер полуострова Рыбачий.

\begin{tabular}{|c|c|c|c|c|c|c|c|c|c|c|}
\hline $\begin{array}{c}\text { Озеро, } \\
\text { глубина }\end{array}$ & $\begin{array}{c}\text { Слой, } \\
\text { см }\end{array}$ & $\mathrm{Cu}$ & $\mathrm{Ni}$ & $\mathrm{Zn}$ & $\mathrm{Co}$ & $\mathrm{Cd}$ & $\mathrm{Pb}$ & As & $\mathrm{Hg}$ & $\mathrm{C}_{\mathrm{d}}$ \\
\hline \multirow{3}{*}{$\begin{array}{c}\text { Рыбачий-1 } \\
10 \text { м }\end{array}$} & $0-0.5$ & 278 & 117 & 126 & 35.5 & 0.485 & 85.1 & 5.40 & 0.644 & \\
\hline & $29-30$ & 34.2 & 20.6 & 62.8 & 3.67 & 0.229 & 5.62 & 1.35 & 0.028 & \\
\hline & $\mathrm{C}_{\mathrm{f}}$ & 8.1 & 5.7 & 2.0 & 9.7 & 2.1 & 15.1 & 4.0 & 23.0 & 69.7 \\
\hline \multirow{2}{*}{$\begin{array}{c}\text { Рыбачий-2 } \\
15 \text { м }\end{array}$} & $\begin{array}{c}0-0.5 \\
31-32\end{array}$ & $\begin{array}{l}131 \\
40.1\end{array}$ & $\begin{array}{c}112 \\
18.2\end{array}$ & $\begin{array}{c}188 \\
38.4\end{array}$ & $\begin{array}{l}12.1 \\
4.42\end{array}$ & $\begin{array}{l}0.202 \\
0.153\end{array}$ & $\begin{array}{l}36.4 \\
6.59\end{array}$ & $\begin{array}{l}7.58 \\
1.39\end{array}$ & $\begin{array}{l}0.462 \\
0.104\end{array}$ & \\
\hline & $\mathrm{C}_{\mathrm{f}}$ & 3.3 & 6.1 & 4.9 & 2.7 & 1.3 & 5.5 & 5.5 & 4.4 & 33.8 \\
\hline \multirow{2}{*}{$\begin{array}{c}\text { Рыбачий-3 } \\
20 \text { м }\end{array}$} & $\begin{array}{l}0-0.5 \\
37-38 \\
\end{array}$ & $\begin{array}{r}132 \\
34.3 \\
\end{array}$ & $\begin{array}{c}108.2 \\
20.4 \\
\end{array}$ & $\begin{array}{l}420 \\
61.0 \\
\end{array}$ & $\begin{array}{l}11.1 \\
9.12 \\
\end{array}$ & $\begin{array}{l}0.705 \\
0.205\end{array}$ & $\begin{array}{l}80.9 \\
5.20 \\
\end{array}$ & $\begin{array}{l}5.40 \\
1.76 \\
\end{array}$ & $\begin{array}{l}0.290 \\
0.035 \\
\end{array}$ & \\
\hline & $\mathrm{C}_{\mathrm{f}}$ & 3.8 & 5.3 & 6.9 & 1.2 & 3.4 & 15.6 & 3.1 & 8.3 & 47.6 \\
\hline \multirow{2}{*}{$\begin{array}{c}\text { Рыбачий-4 } \\
6 \text { м }\end{array}$} & $\begin{array}{l}0-0.5 \\
11-12 \\
\end{array}$ & $\begin{array}{l}94.9 \\
32.7 \\
\end{array}$ & $\begin{array}{l}135 \\
69.8 \\
\end{array}$ & $\begin{array}{l}136 \\
70.4 \\
\end{array}$ & $\begin{array}{l}21.0 \\
16.9 \\
\end{array}$ & $\begin{array}{l}0.568 \\
0.022 \\
\end{array}$ & $\begin{array}{l}50.3 \\
11.0 \\
\end{array}$ & $\begin{array}{l}5.50 \\
10.5 \\
\end{array}$ & $\begin{array}{l}0.105 \\
0.009\end{array}$ & \\
\hline & $\mathrm{C}_{\mathrm{f}}$ & 2.9 & 1.9 & 1.9 & 1.2 & 25.8 & 4.6 & 0.5 & 11.7 & 50.6 \\
\hline \multirow{2}{*}{$\begin{array}{c}\text { Рыбачий-5 } \\
2 \text { м }\end{array}$} & $\begin{array}{l}0-0.5 \\
9-10 \\
\end{array}$ & $\begin{array}{l}41.8 \\
16.0 \\
\end{array}$ & $\begin{array}{l}60.0 \\
35.0 \\
\end{array}$ & $\begin{array}{l}76.2 \\
48.4 \\
\end{array}$ & $\begin{array}{l}5.00 \\
3.06 \\
\end{array}$ & $\begin{array}{l}0.237 \\
0.086 \\
\end{array}$ & $\begin{array}{l}15.3 \\
8.96 \\
\end{array}$ & $\begin{array}{l}1.91 \\
1.25 \\
\end{array}$ & $\begin{array}{l}0.060 \\
0.026\end{array}$ & \\
\hline & $\mathrm{C}_{\mathrm{f}}$ & 2.6 & 1.7 & 1.6 & 1.6 & 2.7 & 1.7 & 1.5 & 2.3 & 15.8 \\
\hline
\end{tabular}

Наибольшее значение степени загрязнения $\left(\mathrm{C}_{\mathrm{d}}\right)$, рассчитанное как сумма коэффициентов загрязнения $\left(\mathrm{C}_{\mathrm{f}}\right.$ - отношение концентрации элемента в поверхностном 1-см слое ДО к содержанию этого элемента в самой нижней части колонки, определяемого как фоновое [7]) восьми TM (Cu, Ni, $\mathrm{Co}, \mathrm{Zn}, \mathrm{Cd}, \mathrm{Pb}, \mathrm{Hg}$ и As), отмечено в оз. Рыбачий-1 (табл. 1). Это озеро характеризуется высокими значениями коэффициента загрязнения $\mathrm{Hg}, \mathrm{Pb}, \mathrm{Co}, \mathrm{Cu}$. Остальные исследуемые озера характеризуются высокими значениями степени загрязнения (согласно классификации [7] $\mathrm{C}_{\mathrm{d}}>32$ ), кроме оз. Рыбачий-5, но и в этом озере значение $\mathrm{C}_{\mathrm{d}}$ находится на границе между умеренным и значительным загрязнением. Практически во всех исследуемых озерах (кроме оз. Рыбачий-5) высокие и значительные величины коэффициента загрязнения имеют глобальные загрязняющие ТM Hg и $\mathrm{Pb}$, a также $\mathrm{Ni}$ и $\mathrm{Cu}$, выбрасываемые комбинатом «Печенганикель».

\section{Литература}

1. Даувальтер В.А. Геоэкология донных отложений озер. Мурманск: Изд-во МГТУ. 2012. 242 с.

2. Даувальтер В.А. Закономерности осадконакопления в водных объектах Европейской субарктики (природоохранные аспекты проблемы) // Автореф. дис. д.г.н. Апатиты: КНЦ РАН. 1999. 52 с.

3. Даувальтер В.А., Кашулин Н.А., Денисов Д.Б. Тенденции изменения содержания тяжелых металлов в донных отложениях озер Севера Фенноскандии в последние столетия // Тр. Карельского научного центра РАН. 2015. № 9. С. 62-75. (3).

4. Моисеенко Т.И., Даувальтер В.А., Ильяшук Б.П., Каган Л.Я., Ильяшук Е.А. Палеоэкологическая реконструкция антропогенной нагрузки // Докл. АН. 2000. Т. 370. № 1. С. 115-118.

5. Удачин В.Н., Аминов П.Г., Филиппова К.А. Геохимия горнопромышленного техногенеза Южного Урала. Екатеринбург. Изд-во: РИО УрО РАН. 2014. 252 с.

6. Gregurek D., Melcher F., Pavlov V.A., Reimann C., Stumpf E.F. Mineralogy and mineral chemistry of snow filter residues in the vicinity of the nickel-copper processing industry, Kola Peninsula, NW Russia // Miner. Petrol. 1999. V. 65. P. 87-111.

7. Håkanson L. An ecological risk index for aquatic pollution control - a sedimentological approach // Water Res. 1980. V. 14. P. 975-1001. 